\title{
Evaluation of Photoinduced Changes in Stability Constants for Metal-Ion Complexes of Crowned Spirobenzopyran Derivatives by Electrospray Ionization Mass Spectrometry
}

\author{
Makoto Nakamura, Kenta Takahashi, Takeshi Fujioka, Shinpei Kado, \\ Hidefumi Sakamoto, and Keiichi Kimura \\ Department of Applied Chemistry, Faculty of Systems Engineering, Wakayama University, Wakayama, Japan
}

The photoinduced changes of metal-ion complexing ability of crowned spirobenzopyran derivatives were studied by using electrospray ionization mass spectrometry (ESI-MS). Stability constants for the complexation with various metal ions in methanol under visibleirradiation conditions were determined for the first time by ESI-MS. It was found that the stability constants of crowned bis(spirobenzopyran) derivatives with metal ions are decreased dramatically by visible irradiation due to the disappearance of powerful ionic interaction between phenolate anion(s) of the merocyanine form of their spirobenzopyran moiety and a metal ion bound to their crown ether moiety, and the decrease in the stability constants is more pronounced for the multivalent metal-ion complexes. A theoretical consideration was also made to attain reliable values of stability complexes for metal-ion complexes of crown compounds. (J Am Soc Mass Spectrom 2003, 14, 1110-1115) (c) 2003 American Society for Mass Spectrometry

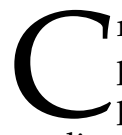
rown ethers and their analogues (crown compounds) are typical host compounds and complex particular metal ions selectively. A lot of studies about metal-ion complexing behavior of crown ethers and their applications for industrial, environmental, and clinical analysis have been reported so far [1-4]. Recently, the functional crown compounds have been designed by introducing functional moieties that control metal-ion complexing abilities of their crown ether moieties, and their complexation behaviors have been studied [5-12]. Previously, we synthesized spirobenzopyran derivatives bearing a crown ether moiety, which we called crowned spirobenzopyran, and studied their metal-ion complexing abilities, photochromism, and applications for devices [13-22]. Spirobenzopyran derivatives, which are typical photochromic compounds, are isomerized from their spirobenzopyran forms to their corresponding colored merocyanine forms by UV irradiation and vice versa by visible irradiation or heating [23-25]. The detailed investigation of crowned spirobenzopyrans has proved that the photochromic crown compounds, when isomerized from the spiropyran form to the merocyanine form under dark and UV irradiation conditions,

Published online August 4, 2003

Address reprint requests to Dr. K. Kimura, Department of Applied Chemistry, Faculty of Systems Engineering, Wakayama University, Sakae-dani 930, Wakayama 640-8510, Japan. E-mail: kkimura@sys.wakayama-u.ac.jp can bind metal ions strongly due to the ionic interaction between phenolate anion(s) of the merocyanine form and a metal ion complexed by the crown ether moiety. On the other hand, the isomerization back to the spiropyran form by visible irradiation weakens the metal-ion complexing ability due to the disappearance of the ionic interaction. It is, therefore, anticipated that the stability constants for metal-ion complexes of crowned spirobenzopyrans are changed by photoirradiation (Scheme 1).

In general, stability constants for crown ether complexes with metal ions can be determined by using calorimetry, potentiometry, absorption spectrophotometry, ${ }^{1} \mathrm{H}-\mathrm{NMR}$ spectroscopy, and so on [26, 27]. The stability constants for metal-ion complexes of crowned spirobenzopyran derivatives are, however, difficult to determine even under dark conditions due to the thermal isomerization for their spirobenzopyran moiety. Recently, a sophisticated determination method for stability constants of crown ether/metal-ion complexes by using electrospray ionization mass spectrometry (ESI-MS) was reported by Kempen et al. [28]. Taking the use of the ESI-MS method, we have successfully determined stability constants for the metal-ion complexes of crowned bis(spirobenzopyran)s under dark conditions [29]. In this paper, we wish to report the evaluation of the metal-ion complex stability constants for crowned spirobenzopyrans 1-3 (Figure 1) under photoirradiation conditions and to prove quantitatively the photoinduced changes in the metal-ion complexing ability of 


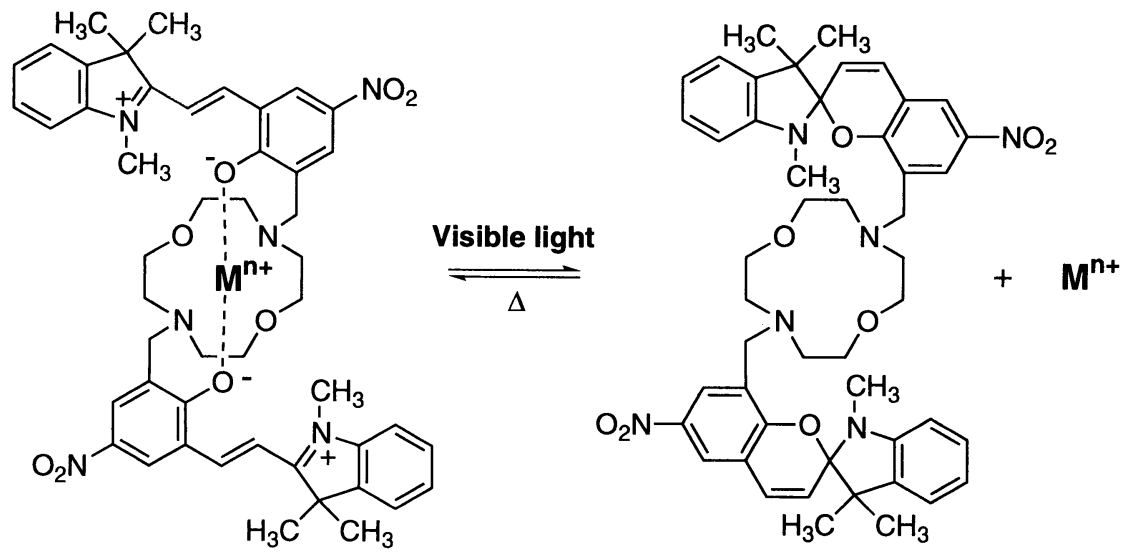

Scheme 1

crowned spirobenzopyran derivatives. To the best of our knowledge, this is the first example for stability constant determination of metal-ion complexes under photoirradiation conditions.

\section{Experimental}

\section{Materials}

Compounds 1, 2, and 3 were synthesized according to a procedure reported previously $[14,29]$. The yields were 52,55 , and $50 \%$ for 1, 2, and 3, respectively. Diaza-12crown-4, diaza-18-crown-6, and monoaza-12-crown-4 were prepared according to reported procedures [3033]. All of the metal salts employed in this study were of analytical grade. The methanol for ESI-MS was distilled.

\section{ESI-MS Measurements}

The photoinduced change of metal-ion complexing ability of crowned spirobenzopyran was studied with an ESI-MS spectrometer (Finnigan LCQ DECA, San Jose, CA). For instance, a methanol solution containing a crowned spirobenzopyran, 18-crown-6, and a metal nitrate $\left(3.0 \times 10^{-5} \mathrm{M}\right.$ each) was allowed to stand for $48 \mathrm{~h}$ under dark conditions for the complete metal-ion complexation. ESI-MS was performed with a sample flow rate of $5 \mathrm{~mL} \mathrm{~min} \operatorname{mos}^{-1}$ at $30^{\circ} \mathrm{C}$ under dark and
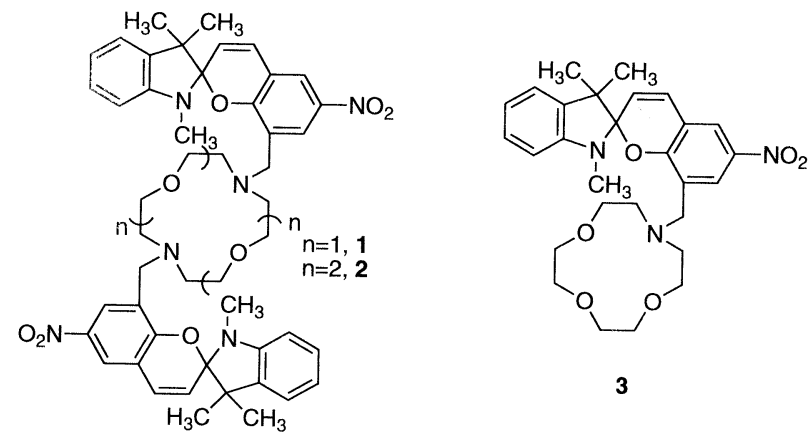

Figure 1. Crowned spirobenzopyrans employed in this study. visible-irradiation conditions. The sheath gas rate was set at 100 units with a $\mathrm{N}_{2}$ pressure of $0.73 \mathrm{MPa}$. Visible light $(>500 \mathrm{~nm}$ ) was obtained by passing light of a 150 W xenon lamp through a color filter (Toshiba V-Y50, Shizuoka, Japan). The ESI-MS measurement under visible irradiation conditions was carried out by injecting a sample solution immediately after visible irradiation of a sample in an injection syringe pump connected with the mass spectrometer for $5 \mathrm{~min}$.

\section{Determination of Stability Constant}

The determination of stability constants was carried out by ESI-MS using a methanol solution containing a pair of crown ethers and a metal nitrate, with a modification of the procedure [28], by the addition of the photoirradiation step. Irradiation of visible light was made as mentioned above. The concentrations for crown ether and metal ion were in the range from $1.0 \times 10^{-5}$ to 3.0 $\times 10^{-5} \mathrm{M}$. The flow rate of the sample solution was 3-10

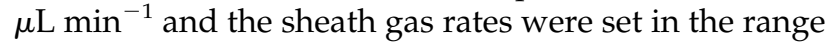
from 20 to 100 units. A calibration graph of a reference complex, of which the stability constant is known, was obtained at first. When a new crown ether was added to the solution containing a reference complex, each of the stability constants $(K)$ for the corresponding 1:1 metalion/crown ether complexes is defined as follows: $K_{\mathrm{R}}=$ $\left[\mathrm{C}_{\mathrm{R}}+\mathrm{M}^{n+}\right] /\left[\mathrm{C}_{\mathrm{R}}\right]_{\mathrm{F}}\left[\mathrm{M}^{n+}\right]_{\mathrm{F}}$ and $K_{\mathrm{N}}=\left[\mathrm{C}_{\mathrm{N}}+\mathrm{M}^{n+}\right] /$ $\left[\mathrm{C}_{\mathrm{N}}\right]_{\mathrm{F}}\left[\mathrm{M}^{n+}\right]_{\mathrm{F}}$. Here, the abbreviations $\mathrm{C}$ and $\mathrm{M}^{n+}$ stand for crown ether and metal ion, respectively. The subscripts $\mathrm{R}, \mathrm{N}$, and $\mathrm{F}$ represent reference and new crown ethers, and free (uncomplexed) species, respectively. The concentration of reference complex $\left[\mathrm{C}_{\mathrm{R}}+\mathrm{M}^{n+}\right]$ was obtained from the calibration graph, and then the concentration of free reference crown ether $\left[C_{R}\right]_{F}$ was calculated as the difference between the total concentration of reference crown ether and the concentration of reference complex, $\left[\mathrm{C}_{\mathrm{R}}\right]_{\mathrm{T}}$ and $\left[\mathrm{C}_{\mathrm{R}}+\mathrm{M}^{n+}\right]$. Since $K_{\mathrm{R}}$ is known, $\left[\mathrm{M}^{n+}\right]_{\mathrm{F}}$ can be calculated. As $\left[\mathrm{M}^{n+}\right]_{\mathrm{F}}$ is a difference between $\left[\mathrm{M}^{n+}\right]_{\mathrm{T}}$ and $\left[\mathrm{C}_{\mathrm{R}}+\mathrm{M}^{n+}\right]+\left[\mathrm{C}_{\mathrm{N}}+\mathrm{M}^{n+}\right]$, a value for $\left[\mathrm{C}_{\mathrm{N}}+\mathrm{M}^{n+}\right]$ can be obtained. The concentration of the free new crown ether is also available from 

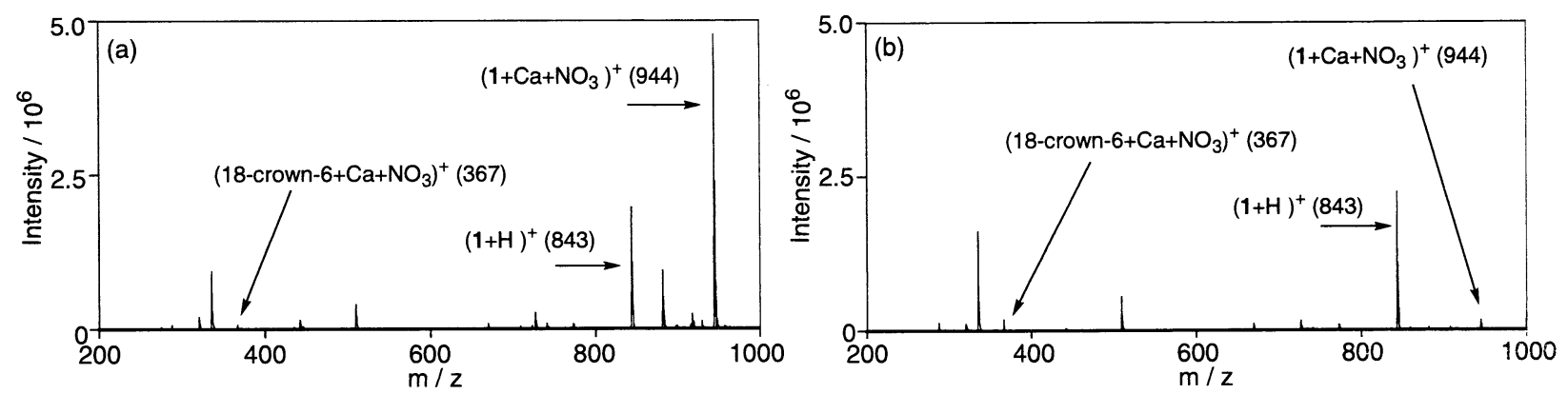

Figure 2. Mass spectra of methanol solutions containing 1, 18-crown-6, and $\mathrm{Ca}^{2+}\left(3.0 \times 10^{-5} \mathrm{M}\right.$ each) under dark conditions (a) and visible irradiation conditions (b).

the difference between $\left[\mathrm{C}_{N}\right]_{\mathrm{T}}$ and $\left[\mathrm{C}_{\mathrm{N}}+\mathrm{M}^{n+}\right]$. The value $K_{\mathrm{N}}$ can be thus calculated from the stability constant definition.

Similarly, stability constants of crown ether/metalion complexes can be determined by mass spectrometry with a methanol solution containing a crown ether and a pair of metal nitrates.

\section{Results and Discussion}

\section{Photoinduced Change of Metal-Ion Complexing Ability}

As mentioned above, the metal-ion complexing ability of crowned spirobenzopyrans is lowered under visible irradiation conditions due to the disappearance of the powerful ionic interaction between the phenolate anion of the merocyanine form and a metal ion bound to the crown ether moiety. The photoinduced changes of complexing ability of Compounds 1-3 were monitored with ESI-MS. Figure 2 shows a competitive $\mathrm{Ca}^{2+}$ complexation between crowned bis(spirobenzopyran) 1 and 18-crown-6 under dark and visible-irradiation conditions. Under dark conditions, the peak intensity for the $\left(1+\mathrm{Ca}+\mathrm{NO}_{3}\right)^{+}$is larger than that for (18-crown-6 + $\left.\mathrm{Ca}+\mathrm{NO}_{3}\right)^{+}$. The spray efficiencies for $1 / \mathrm{Ca}^{2+}$ and 18 -crown-6/ $\mathrm{Ca}^{2+}$ complexes were measured independently with solutions containing the compound and a large excess (100-fold) of $\mathrm{Ca}^{+}$in a preliminary experiment, which showed that the spray efficiency of $1 / \mathrm{Ca}^{2+}$ complex did not exceed that of 18-crown-6/
$\mathrm{Ca}^{2+}$ complex. These results indicate that the $\mathrm{Ca}^{2+}$ affinity of 1 enhanced by the interaction between two phenolate anions of the merocyanine forms of Compound 1 and $\mathrm{Ca}^{2+}$ in its crown ether moiety is much higher than that of the 18-crown-6 moiety itself under dark conditions. Under visible-irradiation conditions, on the other hand, the peak intensity for $(\mathbf{1}+\mathrm{Ca}+$ $\left.\mathrm{NO}_{3}\right)^{+}$was decreased drastically, while that for (18crown-6 $\left.+\mathrm{Ca}+\mathrm{NO}_{3}\right)^{+}$was increased slightly (Figure $2 b)$. The changes in the spectral peak intensity by photoirradiation indicate that the complexing ability of Compound 1 with $\mathrm{Ca}^{2+}$ is reduced by visible irradiation. A similar photoinduced mass-spectral change was observed in the competitive $\mathrm{Na}^{+}$complexation system of Compound 3 and 18-crown-6 (Figure 3$)$. The peak intensity for $(3+\mathrm{Na})^{+}$was decreased by visible irradiation and that for (18-crown- 6 $+\mathrm{Na})^{+}$was increased by contrast, although the spectral peak changes for the 3 system were smaller than that for the 1 system. This finding clearly shows that the metal-ion complexing ability of $\mathbf{3}$ was smaller than that of $\mathbf{1}$ under dark conditions because 3 possesses only one spirobenzopyran moiety. Similar photoinduced mass-spectral changes were found both in the complexing systems of Compounds 1 and 3 with other metal ions. Thus, the photoinduced changes of metal-ion complexing abilities for crowned spirobenzopyrans 1-3 were confirmed qualitatively by using ESI-MS.
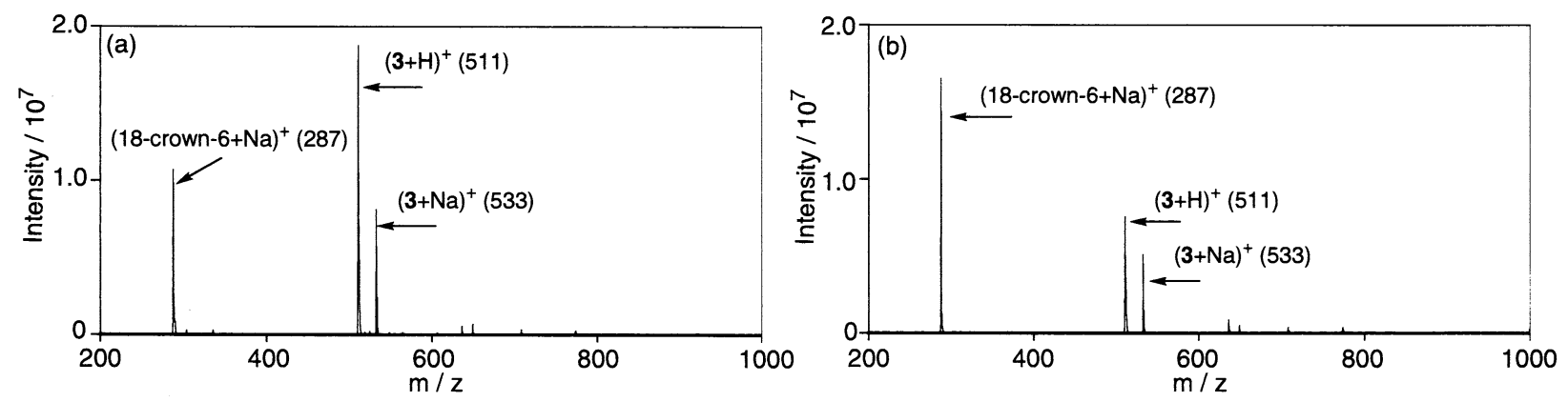

Figure 3. Mass spectra of methanol solutions containing 3, 18-crown-6, and $\mathrm{Na}^{+}\left(3.0 \times 10^{-5} \mathrm{M}\right.$ each) under dark conditions (a) and visible irradiation conditions (b). 
Table 1. Stability constant $(\log K)$ of crown ether/metal-ion complexes determined by ESI-MS

\begin{tabular}{lcccc}
\hline & $\mathrm{Na}^{+}$ & $\mathrm{Ca}^{2+}$ & $\mathrm{Sr}^{2+}$ & $\mathrm{La}^{3+}$ \\
\hline \hline 1 (dark) & $5.0^{\mathrm{a}}$ & $7.8^{\mathrm{b}}$ & $6.7^{\mathrm{c}}$ & $9.2^{\mathrm{c}}$ \\
$\mathbf{1}$ (visible light) & $3.7^{\mathrm{a}}$ & $5.0^{\mathrm{d}}$ & $5.6^{\mathrm{e}}$ & $5.9^{\mathrm{f}}$ \\
diaza-12-crown-4 & $4.0^{\mathrm{a}}$ & $4.7^{\mathrm{d}}$ & $4.5^{\mathrm{g}}$ & $5.4^{\mathrm{f}}$ \\
2 (dark) & $6.1^{\mathrm{a}}$ & $8.4^{\mathrm{b}}$ & $9.0^{\mathrm{h}}$ & $11^{\mathrm{h}}$ \\
(visible light) & $5.1^{\mathrm{a}}$ & $5.0^{\mathrm{d}}$ & $6.2^{\mathrm{e}}$ & $5.8^{\mathrm{f}}$ \\
diaza-18-crown-6 & $3.9^{\mathrm{a}}$ & $4.1^{\mathrm{g}}$ & $5.9^{\mathrm{c}}$ & $5.4^{\mathrm{g}}$ \\
3 (dark) & $\mathrm{i}$ & $4.9^{\mathrm{d}}$ & $5.8^{\mathrm{e}}$ & $5.0^{\mathrm{f}}$ \\
3 (visible light) & $\mathrm{i}$ & $\mathrm{i}$ & $\mathrm{i}$ & $\mathrm{i}$ \\
monoaza-12-crown-4 & $\mathrm{i}$ & $\mathrm{i}$ & $\mathrm{i}$ & $\mathrm{i}$ \\
\hline
\end{tabular}

The $\log K$ values were determined by using

a18-crown-6- $\mathrm{Na}^{+}$as the reference complex,

${ }^{\mathrm{b}}$ cryptand [2.2.2]- $\mathrm{Ca}^{2+}$ as the reference complex

${ }^{\mathrm{c}} 1-\mathrm{Ca}^{2+}$ as the reference complex

d $18-$ crown-6-Ca ${ }^{2+}$ as the reference complex

e18-crown-6- $\mathrm{Sr}^{2+}$ as the reference complex

f18-crown-6- $\mathrm{La}^{3+}$ as the reference complex

${ }^{9}$ diaza-18-crown-6-Sr ${ }^{2+}$ as the reference complex

${ }^{n} 2-\mathrm{Ca}^{2+}$ as the reference complex

iThe reliable values could not be obtained.

\section{Photoinduced Changes of Stability Constants}

The metal-ion complex stability constants (log $K$ values) of Compounds 1-3 obtained under dark and visible irradiation conditions are summarized in Table 1. The significant photoinduced changes in the stability constant, especially with multivalent metal ions, were observed for Compounds $\mathbf{1}$ and $\mathbf{2}$ that carry two spirobenzopyran moieties. For example, in the $\mathrm{La}^{3+}$ complexes of $\mathbf{1}$ and 2, the stability constants were changed by about $3-5$ orders by photoirradiation. It was found by ${ }^{1} \mathrm{H}-\mathrm{NMR}$ spectroscopy that the spirobenzopyran moiety of crowned spirobenzopyran is isomerized almost completely to its corresponding merocyanine form in acetonitrile when crowned spirobenzopyran complexes a metal ion. Also, the cation complexation induced isomerization occurs similarly in methanol. The stability constants for metal-ion complexes of Compounds 1 and 2 in methanol under dark conditions, therefore, correspond to those for their merocyanine forms. On the other hand, it was confirmed by absorption spectrophotometry that the reverse isomerization from the merocyanine form to the spiropyran form can be attained completely by 5 -min visible irradiation in methanol. The thermal isomerization back to the merocyanine form hardly proceeds under dark conditions during the mass spectral measurements owing to the slow thermal isomerization, although a direct photoirradiation in the ESI chamber cannot be made practically. The stability constants for metal-ion complexes of Compounds 1 and $\mathbf{2}$ in methanol under visible irradiation conditions are, therefore, almost the same as those for the corresponding spiropyran forms. The photoinduced changes in the stability constants for metal-ion complexes of crowned bis(spirobenzopyran)s can be attributed to the ionic interaction between phenolate anions on the merocyanine forms and a metal ion bound to the crown ether moiety, as already reported
$[20,22]$. As shown in Table 1, the values for the stability constants for crowned bis(spirobenzopyran)s $\mathbf{1}$ and $\mathbf{2}$ under visible-irradiation conditions resemble those for their corresponding parent crown ethers, diaza-12crown-4 and diaza-18-crown-6, respectively. Their results clearly indicate that the spirobenzopyran moiety under visible irradiation conditions hardly interacts with a metal ion in the crown ether moiety.

The reliable values could not be obtained in the stability constants of Compound 3 that carries only one spirobenzopyran moiety under visible irradiation conditions and of monoaza-12-crown-4, possibly because they are relatively small. It was, however, shown qualitatively by the above-mentioned photoinduced massspectral changes that the metal-ion complexing ability of 3 is definitely changed by photoirradiation in a similar way to crowned bis(spirobenzopyran)s $\mathbf{1}$ and $\mathbf{2}$.

\section{Theoretical Consideration for Stability Constant Determination by ESI-MS}

The ESI-MS method has been applied successfully for the determination of stability constants for metal-ion complexes of the crowned spirobenzopyrans under dark and photoirradiation conditions [28, 29]. In this method, a suitable reference complex must be necessarily selected first to obtain a reliable value of a metal-ion complex stability constant for a new complex. It was claimed by Kempen et al. [28] that the difference in the stability constants between the reference and new complexes should be within a $\log K$ value of \pm 2 for the stability constant determination. We here discuss how the peak intensity changes for a reference complex on addition of a new crown ether affect the accuracy in the stability constants determined by this method. Let us consider a competitive complexation system of two crown ethers (reference and new ones) with a metal ion. Addition of a new crown ether to a complexation system containing a metal ion and a reference crown ether causes a decrease in the mass-spectral peak assigned to the reference crown ether/metal-ion complex due to the competitive metal-ion complexation between the reference and new host crown ethers. A simulation based on the calculation formulas for the ESI-MS method afforded a set of relationships between the stability constant value for the new crown ether/metalion complex (the vertical axis) and the peak intensity changes for the reference crown ether complex which is given as the peak intensity percent of the intensity with a new crown ether to the initial value (the horizontal axis) (Figure 4).

In Figure $4 \mathrm{a}$, if the new complex has a smaller stability constant than that (a $\log K$ value of 3 ) of a reference complex, even addition of a new crown ether in much higher concentrations than that of the reference compound hardly changes the peak intensity for the reference complex. The slight peak intensity change for the reference complex makes it difficult to obtain an 

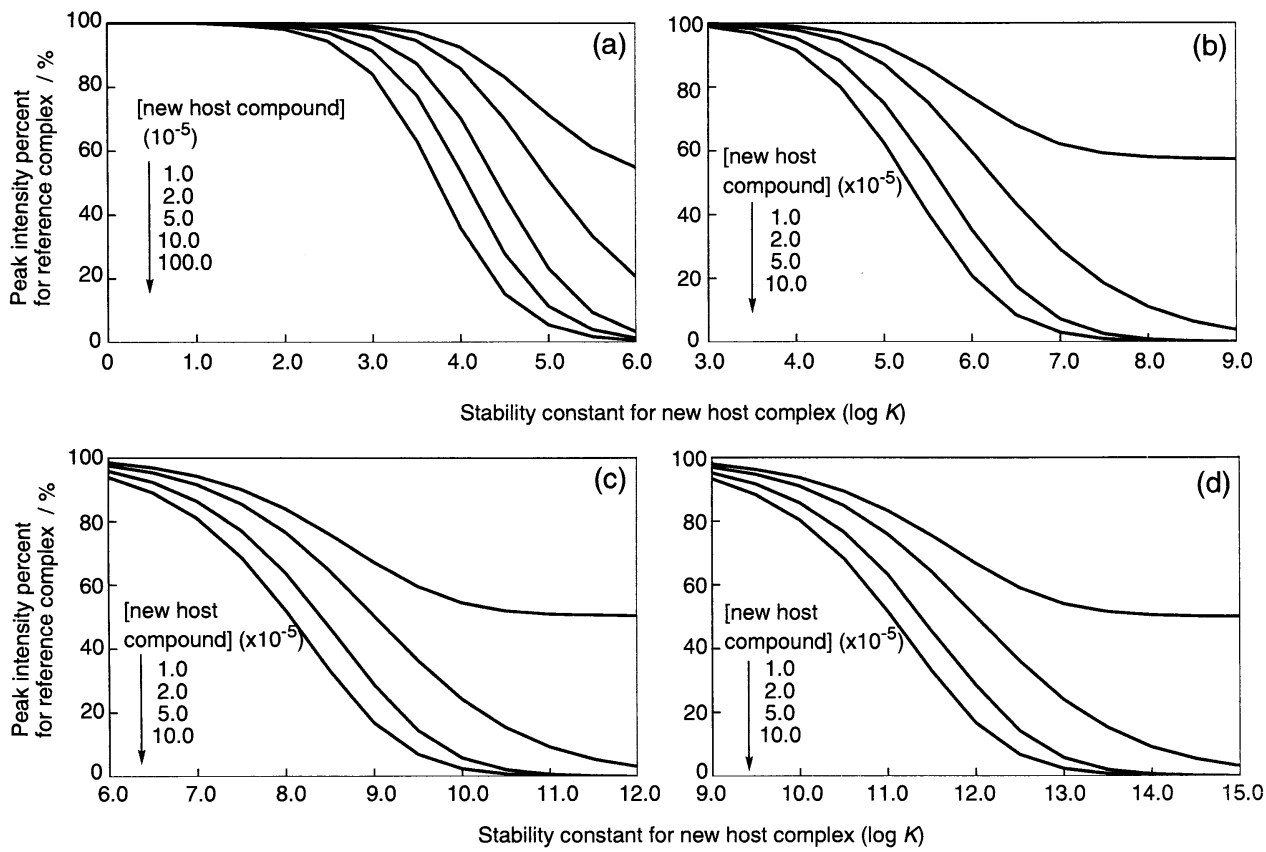

Figure 4. Simulation for peak intensity changes of reference crown ether complexes on addition of new crown ether with different stability constants. The concentrations of reference crown ether and metal ion are $2.0 \times 10^{-5} \mathrm{M}$ each, and the stability constants $(\log K)$ for reference crown ether complexes are $3.0(\mathbf{a}), 6.0(\mathbf{b}), 9.0(\mathbf{c})$, and $12.0(\mathbf{d})$.

accurate value of stability constant for the new crown ether complex. Conversely, if the new complex has a greater stability constant than that (a log $K$ value of 3 ) for the reference complex, the peak intensity of reference complex is decreased significantly on addition of an equimolar amount of a new crown ether. If one would determine a smaller stability constant than a log $K$ value of 3 for a new complex, a crown ether with a stability constant of smaller than a $\log K$ value of 3 should be selected for the reference complex. The calibration graph for a reference crown ether complex with a stability constant smaller than a $\log K$ value of 3 is, however, hard to draw, since the interference by a trace amount of $\mathrm{Na}^{+}$and/or $\mathrm{H}^{+}$in the background cannot be neglected for the calibration calculation. Thus, it turns out that smaller stability constants than a $\log K$ value of 3 cannot be determined practically by using this method. Unfortunately, the ESI-MS method afforded no reliable values for the complex systems of crowned spirobenzopyran 3 and monoaza-12-crown-4, since the stability constants for the metal-ion complexes are probably below 3 .

In Figure $4 b, c$, and d, on the other hand, even when a new complex has a smaller stability constant than that of a reference complex, the peak intensity for the reference complex is decreased remarkably on addition of an equimolar amount of a new crown ether. The figures also indicate that the difference in the stability constants between the reference and new crown ether complexes should be within a $\log K$ value of \pm 1 for the reliable stability constant determination in the sample solution containing at 1:1:1 ratio of reference and new crown ethers and a metal ion. This is because the slopes in the curves become small with the increasing difference in the stability constants between reference and new complexes. Thus, the low slope in the curve causes significant errors.

One might be able to obtain stability constants by adjusting the reference crown ether concentration even if the stability constant difference between reference and new complexes is greater than a $\log K$ value of 2 . However, it also becomes difficult to calculate accurate values for the new complex in this case, because the higher the concentration of the new crown ether is, the smaller the peak intensity change of the reference complex is.

\section{CONCLUSION}

The stability constants of metal-ion complexes for crowned spirobenzopyrans $\mathbf{1}$ and $\mathbf{2}$ were determined for the first time, under photoirradiation conditions by using ESI-MS. The stability constants of Compounds 1 and $\mathbf{2}$ were decreased significantly by irradiation of visible light, and the tendency became more remarkable in the multivalent metal-ion complexes whose stability constants were relatively high under dark conditions. The reliability for the stability constants was proved by the simulation. The photoinduced changes in the metalion complexing ability of crowned spirobenzopyrans were thus confirmed quantitatively by the stability constant determination in this study. 


\section{Acknowledgments}

This work was partially supported by a Grant-in-Aid-for Scientific Research (B) (no. 15350043) from the Ministry of Education, Culture, Sports, Science, and Technology, Japan.

\section{References}

1. Pedersen, C. J. Cyclic Polyethers and Their Complexes with Metal Salts. J. Am. Chem. Soc. 1967, 89, 7017-7036.

2. Abel, E.; Maguire, G. E. M.; Murillo, O.; Suzki, I.; Wall, S. L. D.; Gokel, G. W. Hydraphile Channels: Structural and Fluorescent Probes of Position and Function in a Phospholipid Bilayer. J. Am. Chem. Soc. 1999, 121, 9043-9052.

3. Synthetic Multidentate Macrocyclic Compounds; Izatt, R. M.; Christensen, J.J., Eds.; Academic Press: New York, NY, 1978;

4. Dietrich, B.; Viout, P. Lehn, J.-M. In Macrocyclic Chemistry; VCH: New York, NY, 1993, pp 167-369.

5. Vögtle, F. In Supramolecular Chemistry; Wiley: New York, NY, 1993; pp 207-229.

6. de Silva, A. P.; Gunaratne, H. Q. N.; Gunnlaugsson, T.; Huxley, A. J. M.; McCoy, C. P.; Rademacher, J. T.; Rice, T. E. Signaling Recognition Events with Fluorescent Sensors and Switches. Chem. Rev. 1997, 97, 1515-1566.

7. Aoki, S.; Kawatani, H.; Goto, T.; Kimura, E.; Shiro, M. A Double-Functionalized Cyclen with Carbamoyl and Dansyl Groups (Cyclen $=1,4,7,10-$ Tetraazacyclododecane): A Selective Fluorescent Probe for $\mathrm{Y}^{3+}$ and $\mathrm{La}^{3+}$. J. Am. Chem. Soc. 2001, 123, 1123-1132.

8. Yamauchi, A.; Hayashita, T.; Kato, A.; Nishizawa, S.; Watanabe, M.; Teramae, N. Selective Potassium Ion Recognition by Benzo-15-Crown-5 Fluoroionophore/-Cyclodextrin Complex Sensors in Water. Anal. Chem. 2000, 72, 5841-5846.

9. Lowe, M. P.; Parker, D.; Reany, O.; Aime, S.; Botta, M.; Castellano, G.; Gianolio, E.; Pagliarin, R. pH-Dependent Modulation of Relaxivity and Luminescence in Macrocyclic Gadolinium and Europium Complexes Based on Reversible Intramolecular Sulfonamide Ligation. J. Am. Chem. Soc. 2001, 123, 7601-7609.

10. Mizukami, S.; Nagano, T.; Urano, Y.; Odani, A.; Kikuchi, K. A Fluorescent Anion Sensor that Works in Neutral Aqueous Solution for Bioanalytical Application. J. Am. Chem. Soc. 2002, 124, 3920-3925.

11. Inouye, M.; Ueno, M.; Tauchiya, K.; Nakayama, N.; Konishi, T.; Kitao, T. Alkali-Metal Cation Recognition Induced Isomerization of Spirobenzopyrans and Spironaphthoxazins Possessing a Crown Ring as a Recognition Site: Multifunctional Artificial Receptors. J. Org. Chem. 1992, 57, 5377-5383.

12. Inouye, M.; Akamatsu, K.; Nakazumi, H. New Crown Spirobenzopyrans as Light- and Ion-Responsive Dual-Mode Signal Transducers. J. Am. Chem. Soc. 1997, 119, 9160-9165.

13. Kimura, K.; Yamashita, T.; Yokoyama, M. Cation-Specific Isomerization of Crowned Spirobenzopyrans. J. Chem. Soc. Chem. Commun. 1991, 147-148.

14. Kimura, K.; Yamashita, T.; Yokoyama, M. Syntheses, Cation Complexation, Isomerization, and Photochemical CationBinding Control of Spirobenzopyrans Carrying a Monoazacrown Moiety at the 8-Position. J. Chem. Soc. Perkin Trans. 2 1992, 613-619.

15. Kimura, K.; Sumida, M.; Yokoyama, M. Drastic Metal-Ion Enhancement in Photoinduced Aggregation of Copolymers Carrying Crown Ether and Spirobenzopyran Moieties. Chem. Commun. 1997, 1417-1418.

16. Tanaka, M.; Kamada, K.; Ando, H.; Kitagaki, T.; Shibutani, Y.; Kimura, K. Synthesis and Photochromism of Crowned Spirobenzothiapyran: Facilitated Photoisomerization by Coopera- tive Complexation of Crown Ether and Thiophenolate Moieties with Metal Ions. J. Org. Chem. 2000, 65, 4342-4347.

17. Tanaka, M.; Nakamura, M.; Salhin, M. A. A.; Ikeda, T.; Kamada, K.; Ando, H.; Shibutani, Y.; Kimura, K. Synthesis and Photochromism of Spirobenzopyran Derivatives Bearing an Oxymethylcrown Ether Moiety: Metal-Ion Induced Switching Between Positive and Negative Photochromisms. J. Org. Chem. 2001, 66, 1533-1537.

18. Kimura, K.; Yamashita, T.; Yokoyama, M. Photochemical Control of Ionic Conduction by Crowned Spirobenzopyran. Chem. Lett. 1991, 965-968.

19. Kimura, K.; Yamashita, T.; Yokoyama, M. Photochemical Switching of Ionic Conductivity in Composite Films Containing a Crowned Spirobenzopyran. J. Phys. Chem. 1992, 96, $5614-5617$

20. Kimura, K.; Utsumi, T.; Teranishi, T.; Yokoyama, M.; Sakamoto, H.; Okamoto, M.; Arakawa, R.; Moriguchi, H.; Miyaji, Y. High La ${ }^{\text {III }}$ Affinity of a Bis(spirobenzopyran) Azacrown Ether and Photoinduced Switching of Its Ion Selectivity between Multivalent Metl Ions. Angew. Chem. Int. Ed. Engl. 1997, 36, 2452-2454.

21. Kimura, K.; Sakamoto, H.; Kado, S.; Arakawa, R.; Yokoyama, M. Studies on Metal-Ion Complex Formation of Crown Ether Derivatives Incorporating a Photoionizable Spirobenzopyran Moiety by Electrospray Ionization Mass Spectrometry. Analyst 2000, 125, 1091-1095.

22. Kimura, K.; Teranishi, T.; Yokoyama, M.; Yajima, S.; Miyake, S.; Sakamoto, H.; Tanaka, M. Cation Complexation, Isomerization, and Photoresponsive Ionic Conduction of a Crown Ether Derivative Carrying Two Spirobenzopyran Units. J. Chem. Soc. Perkin Trans. 2 1999, 199-204.

23. Sunamoto, J.; Iwamoto, K. Akutagawa M.; Nagase, M.; Kondo, H. Rate Control by Restricting Mobility of Substrate in Specific Reaction Field. Negative Photochromism of Water-Soluble Spiropyran in AOT Reversed Micelles. J. Am. Chem. Soc. 1982, 104, 4904-4907.

24. Sunamoto, J.; Iwamoto, K.; Mohri, Y.; Kominato, T. Liposomal Membranes. 13. Transport of an Amino Acid Across Liposomal Bilayers as Mediated by a Photoresponsive Carrier. J. Am. Chem. Soc. 1982, 104, 5502-5504.

25. Winkler, J. D.; Deshayes, K.; Shao, B. Photodynamic Transport of Metal Ions. J. Am. Chem. Soc. 1989, 111, 769-770.

26. Izatt, R. M.; Pawlak, K.; Bradshaw, J. S.; Bruening, R. L. Thermodynamic and Kinetic Data for Macrocycle Interactions with Cations and Anions. Chem. Rev. 1991, 91, 1721-2085.

27. Inoue, Y. Hakushi, T. In Cation Binding by Macrocycles; Inoue Y.; Gokel, G. W., Ed; Marcel Dekker: New York, NY, 1990; pp $1-110$.

28. Kempen, E. C.; Brodbelt, J. S. A Method for the Determination of Binding Constants by Electrospray Ionization Mass Spectrometry. Anal. Chem. 2000, 72, 5411-5416.

29. Nakamura, M.; Fujioka, T.; Sakamoto, H.; Kimura, K. High Stability Constants for Multivalent Metal-Ion Complexes of Crown Ether Derivatives Incorporating Two Spirobenzopryan Moieties. New J. Chem. 2002, 26, 554-559.

30. Krakowiak, K. E.; Bradshaw, J. S. Zamecka-Krakowiak D. J. Synthesis of Aza-Crown Ethers. Chem. Rev. 1989, 89, 929-972.

31. Weber, E.; Vögtle, F. Neue Kronenäther und ihre Alkalimetallion-Komplexe. Chem. Ber. 1976, 109, 1803-1831.

32. Dietrich, B.; Lehn, J.-M.; Sauvage, J. P.; Blanzet, J. Syntheses et Proprietes Physiques de Systemes Diaza-Pplyoxa-Macrobicycliques. Tetrahedron 1973, 29, 1629-1645.

33. Calverley, M.; Dale, J. 1,4,7-Trioxa-10-azacyclododecane and Some N-Substituted Derivatives; Synthesis and Cation Complexing. Acta Chem. Scand. B. 1982, 36, 241-247. 